Supplement of The Cryosphere, 14, 4525-4551, 2020

https://doi.org/10.5194/tc-14-4525-2020-supplement

(C) Author(s) 2020. This work is distributed under

the Creative Commons Attribution 4.0 License.

(c) (1)

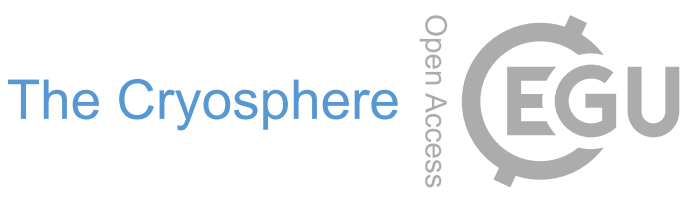

Supplement of

\title{
The cryostratigraphy of the Yedoma cliff of Sobo-Sise Island (Lena delta) reveals permafrost dynamics in the central Laptev Sea coastal region during the last $52 \mathrm{kyr}$
}

Sebastian Wetterich et al.

Correspondence to: Sebastian Wetterich (sebastian.wetterich@awi.de)

The copyright of individual parts of the supplement might differ from the CC BY 4.0 License. 


\section{Supplementary material}

Figure S1: Scores of mean robust endmembers and explained variances of the robust endmember modelling approach (EMMA) following Dietze and Dietze (2019) for a total of 56 GSD matrices from profiles SOB18-01, SOB18-03 and SOB1806 representing the Yedoma IC and excluding the uppermost Holocene cover.
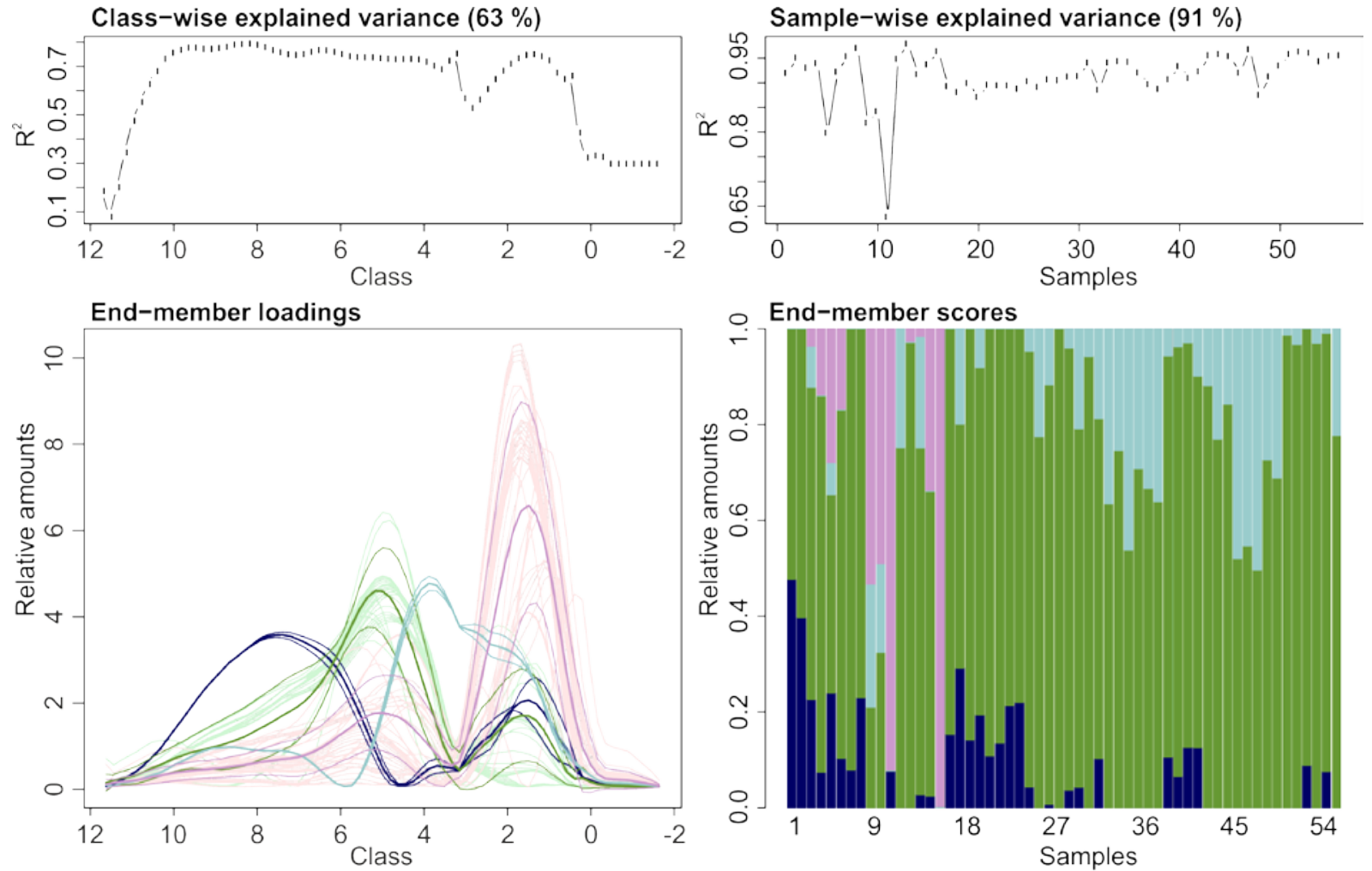

End-member ID (mode position | explained variance)

$\operatorname{EM} 1(7.4 \mid 9.1 \%) \quad \operatorname{EM} 2(5 \mid 39 \%) \quad \operatorname{EM} 3(3.7 \mid 18 \%) \quad \operatorname{EM} 4(1.7 \mid 34 \%)$ 
Figure S2: Bayesian age-depth model output using the package rbacon 2.3 (2.3.9.1) (Blaauw and Christen, 2019) in R version 3.6.1 (R Core Team, 2019) per profile (a) SOB18-01, (b) SOB18-03 and (c) SOB18-06. Sample heights above rivel level were transferred into depths to run the model. The upper panels show the Markov Chain Monte Carlo iterations (left panel), the prior (green curves) and posterior (grey histograms) distributions for the accumulation rate (middle left panel) and memory (middle right panel), and the prior distribution for hiatus size (right panel). The bottom panel shows the calibrated radiocarbon dates (transparent blue) and the age-depth model with 95\% confidence intervals (grey lines) and single 'best' model based on the weighted mean age for each depth (red curve). Panel explanations following Blaauw and Christen (2019).

(a) profile SOB18-01
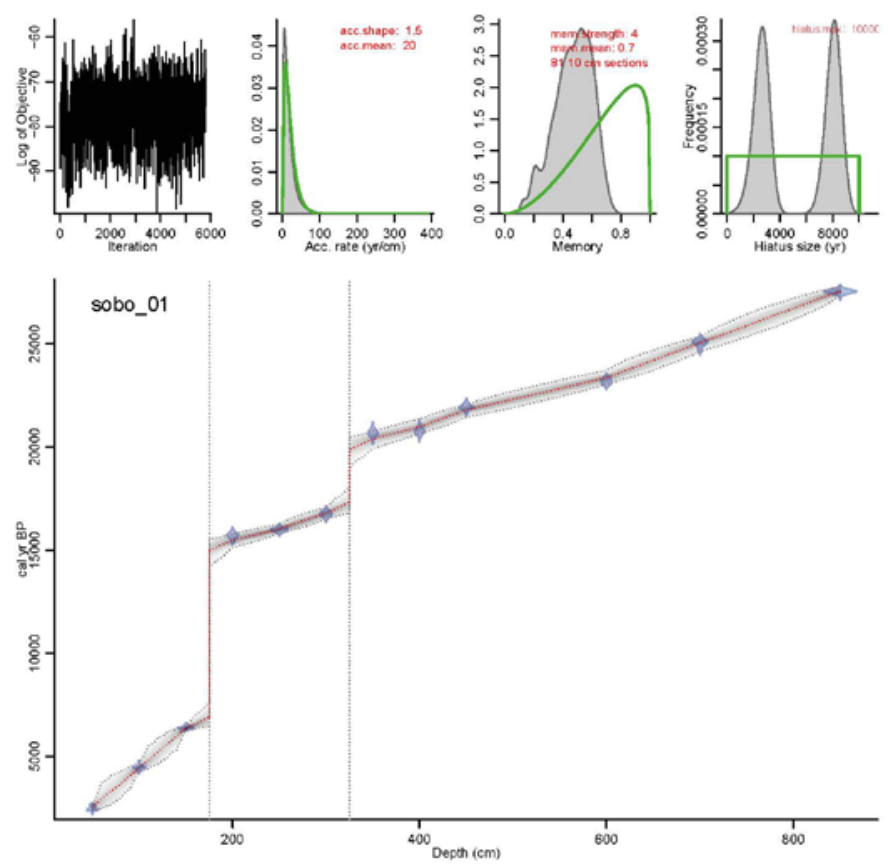
(b) profile SOB18-03
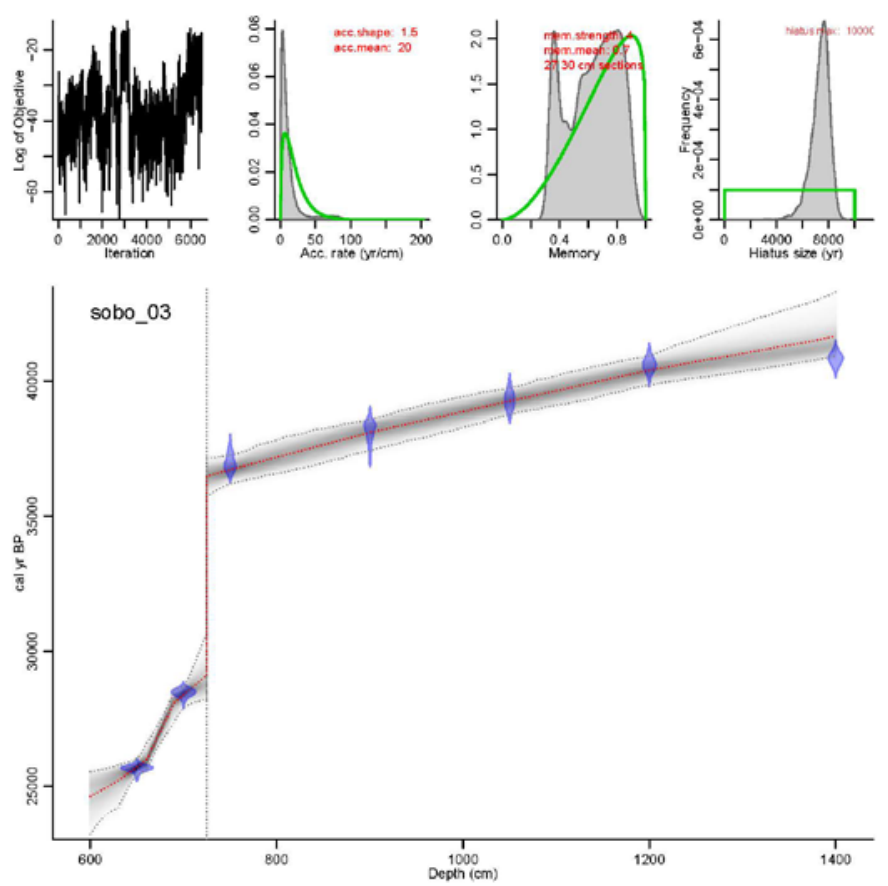

(c) profile SOB18-06
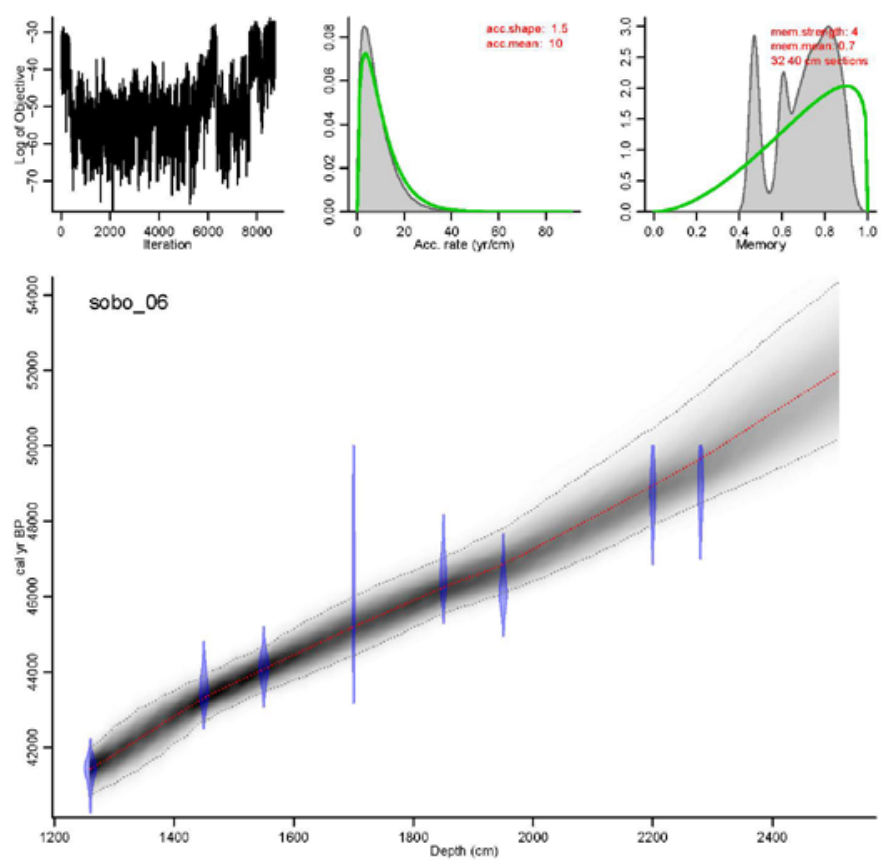